University of Nebraska - Lincoln

DigitalCommons@University of Nebraska - Lincoln

\title{
2-2009
}

\section{Haloform adsorption on crystalline copolymer films of vinylidene fluoride with trifluoroethylene}

\author{
Jie Xiao \\ University of Nebraska-Lincoln, jie.xiao@helmholtz-berlin.de \\ Carolina C. Ilie \\ University of Nebraska-Lincoln \\ Ning Wu \\ University of Nebraska-Lincoln \\ Keisuke Fukutani \\ University of Nebraska-Lincoln \\ Peter A. Dowben \\ University of Nebraska-Lincoln, pdowben@unl.edu
}

Follow this and additional works at: https://digitalcommons.unl.edu/physicsdowben

Part of the Physics Commons

Xiao, Jie; Ilie, Carolina C.; Wu, Ning; Fukutani, Keisuke; and Dowben, Peter A., "Haloform adsorption on crystalline copolymer films of vinylidene fluoride with trifluoroethylene" (2009). Peter Dowben Publications. 235.

https://digitalcommons.unl.edu/physicsdowben/235

This Article is brought to you for free and open access by the Research Papers in Physics and Astronomy at DigitalCommons@University of Nebraska - Lincoln. It has been accepted for inclusion in Peter Dowben Publications by an authorized administrator of DigitalCommons@University of Nebraska - Lincoln. 
Published in Surface Science 603:3 (February 1, 2009), pp. 513-517; doi: 10.1016/j.susc.2008.12.008

Copyright (c) 2008 Elsevier B.V. Used by permission. http://www.elsevier.com/locate/susc

Submitted August 28, 2008; accepted December 11, 2008; published online December 24, 2008.

\title{
Haloform adsorption on crystalline copolymer films of vinylidene fluoride with trifluoroethylene
}

\author{
Jie Xiao, Carolina C. Ilie, Ning Wu, Keisuke Fukutani, and P. A. Dowben \\ Department of Physics and Astronomy and The Nebraska Center for Materials and Nanoscience, \\ Behlen Laboratory of Physics, P.O. Box 880111, University of Nebraska-Lincoln, Nebraska 68588-0111, USA \\ Corresponding author - Peter A. Dowben, tel 402 472-9838, fax 402 472-2879, email pdowben@unl.edu \\ Present address for C. C. Ilie: Department of Physics, State University of New York at Oswego, 123A Snygg Hall, Oswego, NY 13126, USA.
}

\begin{abstract}
Reversible bromoform adsorption on crystalline polyvinylidene fluoride with 30\% of trifluoroethylene, P(VDF-TrFE 70:30) was examined by photoemission and inverse photoemission spectroscopies. The adsorption of bromoform on this polymer surface is associative and reversible. Molecular bromoform adsorption appears to be an activated process at $120 \mathrm{~K}$ with enhanced adsorption following the initial adsorption of bromoform. Strong intermolecular interactions are also implicated in the presence of a weak shake off or screened photoemission final state, whose intensity scales with the unscreened photoemission final state.
\end{abstract}

Keywords: halocarbon adsorption, poly(vinylidene fluoride-trifluoroethylene), surface science of polymers

\section{Introduction}

The adsorption of halocarbons on metal surface is a lively area of activity in surface science dating back more than two decades [1]. Although the electronic structure of the haloforms is very similar [2], most of the emphasis has been on chloroform adsorption [3-8]. Recently, bromoform [9, 10] and chloroform [11, 12] adsorption and their photodecomposition on molecular films like ice have been investigated. Crystalline and dipole ordered surfaces of ice are, however, extremely difficult to prepare [13-16], so the study of bromoform adsorption on the crystalline-like dipole ordered copolymer polyvinylidene fluoride with $30 \%$ of trifluoroethylene, $\mathrm{P}(\mathrm{VDF}-\mathrm{TrFE}$ 70:30) provides a compelling reference comparison.

Copolymer films of polyvinylidene fluoride with trifluoroethylene have a number of advantages for the surface scientist interested in adsorption and absorption studies on a molecular surface. Ultra-thin crystalline films of these polymers can be formed: thin enough for sufficient thermal conductivity. The Langmuir-Blodgett technique for fabricating the $\mathrm{P}(\mathrm{VDF}-\mathrm{TrFE})$ films provides sufficient crystalline order for scanning tunneling microscopy [17-21], low energy electron diffraction $[18,19]$ and even band structure mappings [18-22], so that in many respects adsorbate interactions can be investigated in much the same way as traditional surface science studies undertaken on single crystal metal surfaces.

Chloroform $\left(\mathrm{CHCl}_{3}\right)$ adsorption on calixarene molecular films has been studied [23], but bromoform $\left(\mathrm{CHBr}_{3}\right)$ adsorption on the copolymer polyvinylidene fluoride with trifluoroethylene, $\mathrm{P}(\mathrm{VDF}-$
TrFE 70:30) provides a better opportunity to study dipole interactions as this substrate is a ferroelectric polymer [24-27] with well ordered surface dipoles below $290 \mathrm{~K}$ [27-29]. Water ice is not generally considered a ferroelectric, although the water dipoles can order, so dipolar interactions cannot a priori be excluded.

\section{Experimental}

Ultrathin ferroelectric films of copolymer like $70 \%$ vinylidene fluoride $-\left(\mathrm{CH}_{2}-\mathrm{CF}_{2}\right)$ - with $30 \%$ of trifluoroethylene $-\left(\mathrm{CHF}-\mathrm{CF}_{2}\right)-$ , P(VDF-TrFE 70:30) by molecular percent (not by weight percent) were fabricated by Langmuir-Blodgett (LB) deposition technique on graphite substrates from the water subphase, which can produce films with thickness ranging from 1 monolayer (nominally $1 \mathrm{ML}$, or about $0.5 \mathrm{~nm}$ thick) to over $500 \mathrm{ML}[25,26]$. The bulk crystallinity has been confirmed by X-ray diffraction on films from 4 to 150 ML thick [20, 30, 31]. P(VDF-TrFE 70:30) samples of five molecular layers thick, on graphite, were cleaned in ultrahigh vacuum by annealing at $110^{\circ} \mathrm{C}$ before and after each experiment for $30 \mathrm{~min}$, which has proved to be an effective recipe in prior studies $[17,19-21,27-29]$. The bromoform $\left(\mathrm{CHBr}_{3}\right)$ was admitted to the ultrahigh vacuum system through a standard leak valve and the exposures are denoted in Langmuirs ( $1 \mathrm{~L}=10^{-6}$ Torr s).

The combined ultraviolet photoemission (UPS) and inverse photoemission (IPES) spectra were used to characterize the molecular orbital placement of both occupied and unoccupied orbitals of the polymer substrate and the bromoform adsorbate. In both photoemission and inverse photoemission measurements, the bind- 
ing energies are referenced with respect to the Fermi edge of gold or tantalum, in intimate contact with the sample surface. The IPES were obtained by using variable incident energy electrons while measuring the emitted photons at a fixed energy $(9.7 \mathrm{eV})$ using a Geiger-Müller detector [19-21, 32]. The instrumental linewidth is $\sim 400 \mathrm{meV}$, as described elsewhere [19-21, 32]. The angle integrated photoemission (UPS) studies were carried out in the same vacuum system using a helium lamp at $h v=21.2 \mathrm{eV}$ (He I) or a Phi X-ray source with a $\mathrm{Mg}$ anode $(h v=1253.6 \mathrm{eV})$ and a Phi hemispherical electron analyzer with an angular acceptance of $\pm 10^{\circ}$ or more as described in detail elsewhere [32], unless stated otherwise.

\section{Model calculations}

To gain some insight into the valence and conduction band molecular orbitals, the combined photoemission and inverse photoemission spectra were compared with semiempirical method NDO-PM3 (neglect of differential diatomic overlap, parametric model number 3) model calculations based on Hartree-Fock formalism. This is a qualitative simplistic comparison and we expect a number of differences between experiment and theory, particular as this is a ground state calculation and photoemission and inverse photoemission are final state spectroscopies. These PM3 model calculations are based on a single chain so a closing of the highest occupied molecular orbital to lowest unoccupied molecular orbital gap due to intermolecular interactions [33] within the $\mathrm{P}(\mathrm{VDF}-\mathrm{TrFE})$ film (solid state effects) and band structure, particularly given the large band dispersion evident in the unoccupied molecular orbitals [21,22] is not taken into account.

Although PM3 is a simplistic semiempirical calculation, density functional theory (DFT) is notorious for under estimating the band gap sometimes by a factor of 2 or more [34], particularly for molecular systems, and must be rescaled for comparison with experiment [35], particularly final state spectroscopies like photoemission and inverse photoemission. For molecular adsorbate systems on $\mathrm{P}(\mathrm{VDF}-\mathrm{TrFE})$, we have found that the strength of DFT is in modeling structure and site [15], while PM3 provides a far better picture of electronic structure [15, 36-38].

To compare the model calculations with experiment (Figure 1), we applied Gaussian envelopes of $1 \mathrm{eV}$ full width half maximum to each calculated molecular orbital energy (Eigen value) to account for the solid state broadening in photoemission and then summing. These model density of states calculations are rigidly shifted in energy by $5.3 \mathrm{eV}$ and then compared with the combined photoemission and inverse photoemission data, as indicated in Figure 1. The $5.3 \mathrm{eV}$ energy shift applied to the calculated orbital energies is, for the most part, representative of work function $\Phi$ equal to the difference of vacuum energy $E_{\mathrm{vac}}$ and Fermi level $E_{\mathrm{F}}$. This rigid energy shift is applied to the calculated electronic structure uniformly. No corrections are made for final state effects nor matrix element effects, so the comparison with experiment is simplistic, but nonetheless still often successful [15, 19-21].

\section{Bromoform adsorption on substrates of copolymer polyvinylidene fluoride with trifluoroethylene}

As seen in Figure 1, the highest occupied molecular orbital (HOMO) to lowest unoccupied molecular orbital (LUMO) gap for copolymer polyvinylidene fluoride with trifluoroethylene, P(VDFTrFE 70:30) is much smaller than expected from the model calculations, as noted previously [37, 38], but the differences from expectation are greatest for the unoccupied molecular orbitals where there are significant band structure effects [21, 22].

Following bromoform adsorption on P(VDF-TrFE) at $120 \mathrm{~K}$, there is a clear suppression of the $\mathrm{P}(\mathrm{VDF}-\mathrm{TrFE})$ photoemission

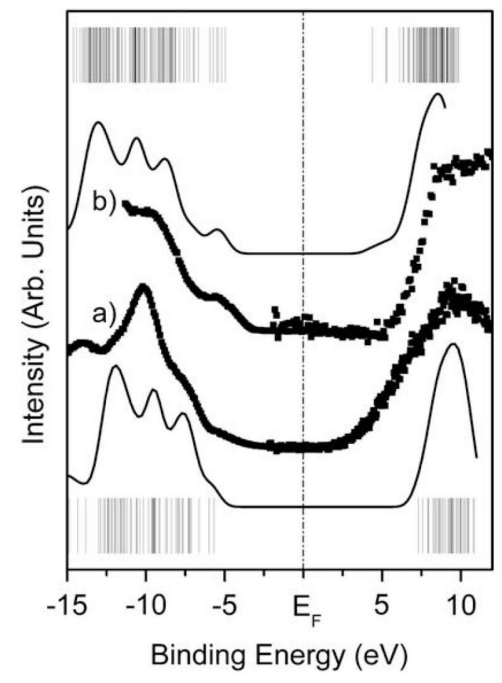

Figure 1. The comparison of the model density of states for PVDFTrFE at the extreme bottom (thin line) with the combined UPS (left) and IPES (right) experimental spectra for clean PVDF-TrFE (a) is shown. Also shown is the comparison of (b) the combined UPS (left) and IPES (right) experimental spectra for $30 \mathrm{~L}$ of bromoform adsorbed on PVDF-TrFE film at $120 \mathrm{~K}$ to the model single molecule density of states for bromoform at the extreme top of the figure (thin line). The molecular orbital Eigen values are shown for P(VDF-TrFE) at the bottom and for bromoform at the top as well. Binding energies are stated in terms of $\mathrm{E}-E_{\mathrm{F}}$.

features, and the density of states due to the lowest unoccupied molecular orbital contributions to the inverse photoemission spectra. The new features introduced by bromoform match the expected model calculations of the molecular orbitals of bromoform (Figure 1). This tends to suggest that bromoform adsorption "wets" the surface of $\mathrm{P}(\mathrm{VDF}-\mathrm{TrFE})$, unlike water adsorption on hexagonal ice [16]. This absence of water wetting hexagonal ice surface upon adsorption has been attributed to the absence of lone pair electrons or dangling $\mathrm{OH}$ bonds for the surface of hexagonal ice [16], but water will wet $\mathrm{P}(\mathrm{VDF}-\mathrm{TrFE})$ to form hexagonal ice [15].

The HOMO-LUMO gap, as determined from the combined photoemission and inverse photoemission, is smaller than expected for $\mathrm{P}(\mathrm{VDF}-\mathrm{TrFE})$. For bromoform adsorbed on $\mathrm{P}(\mathrm{VDF}-$ TrFE) at $120 \mathrm{~K}$, the HOMO-LUMO gap is larger than expected based on the model semiempirical molecular calculations, as seen in Figure 1. This may be due to final state effects $[39,40]$ that become more pronounced with decreasing temperature and the increased bromoform coverages. The decreased screening of an adsorbate on a poorly conducting substrate would tend to open up the experimental HOMO-LUMO gap in the photoemission and inverse photoemission final state by effectively increasing and decreasing the binding energies, respectively $[39,40]$.

Bromoform adsorption is also evident in the X-ray photoemission of the bromine $3 \mathrm{~d}$ core level, where the intensity increases with increasing exposure, as seen in Figure 2. The binding energy of $72.1 \pm 0.1 \mathrm{eV}$ at low bromoform exposure increases to $72.6 \pm 0.1 \mathrm{eV}$ at higher exposures to $\mathrm{P}(\mathrm{VDF}-\mathrm{TrFE})$ at $120 \mathrm{~K}$, as summarized in Figure $3 c$. We do not resolve the $B r 3 d_{5 / 2}$ to $3 d_{3 / 2}$ core level splitting, expected to be about $1 \mathrm{eV}$. In spite of our inability to resolve the $3 d_{5 / 2}$ and $3 d_{3 / 2}$ core levels, the bromine $3 \mathrm{~d}$ XPS features exhibit larger binding energies than expected for the $3 d_{5 / 2}$ core level: a binding energy of $70.3 \mathrm{eV}$ has been measured for condensed bromophenol blue [41], although the binding energy for gaseous bromoform is $76.8 \mathrm{eV}$ [42]. This is consistent with the higher oxidation state of bromoform although final state effects (as mentioned above) could contribute to increased binding 


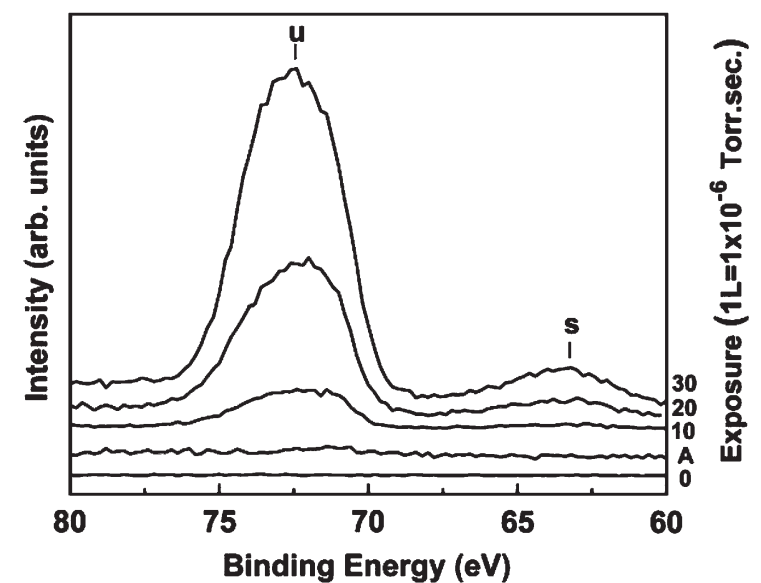

Figure 2. The sequence of photoemission spectra of $5 \mathrm{ML}$ thick $\mathrm{P}\left(\mathrm{VDF}-\mathrm{TrFE}\right.$ 70:30) films at $120 \mathrm{~K}$ before and after $\mathrm{CHBr}_{3}$ exposure $\left(10 \mathrm{~L}, 20 \mathrm{~L}, 30 \mathrm{~L}\right.$; where 1 Langmuir $(\mathrm{L})=1 \times 10^{-6}$ Torr s). The bromine $3 \mathrm{~d}_{3 / 2}$ and $3 \mathrm{~d}_{5 / 2}$ core levels are superposed around $73 \mathrm{eV}$ and the possible screened final state feature is seen at $63 \mathrm{eV}$ binding energy. Spectrum A is after annealing to room temperature showing that molecular adsorption of bromoform on PVDF is reversible. The screened (s) and unscreened $(\mathrm{u})$ final states are indicated.

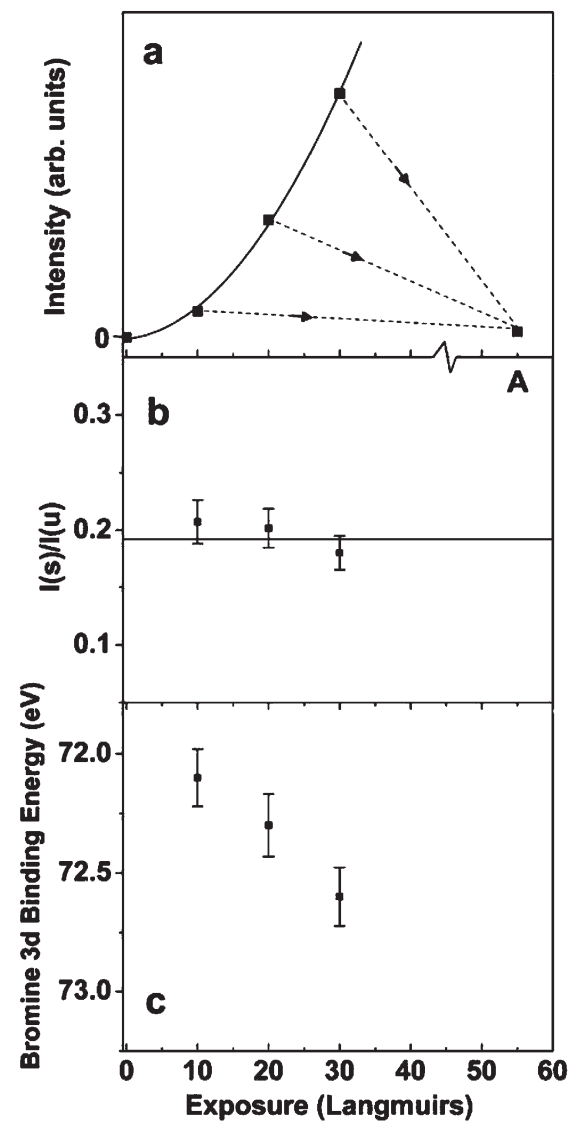

Figure 3. The XPS bromine $3 \mathrm{~d}$ core level intensity as a function of bromoform exposure to PVDF-TrFE at $120 \mathrm{~K}$ (a). The arrows indicate the bromine $3 \mathrm{~d}$ core level intensities observed after annealing the P(VDFTrFE) substrate (point A). The ratio of the $63 \mathrm{eV}$ binding energy photoemission feature relative to the bromine $3 \mathrm{~d}$ core level intensity at $72-73 \mathrm{eV}$ binding energy is also plotted (b). The bromine $3 \mathrm{~d}$ core level binding energies are seen to increase with bromoform coverage (c). energies as the polymer substrate is a nominal dielectric. For reference, much higher binding energies, in the region of $74 \mathrm{eV}$, have been observed for thick bromoform multilayers adsorbed on graphite but similar $\mathrm{Br} 3 \mathrm{~d}$ binding energies (to those observed for bromoform on $\mathrm{P}(\mathrm{VDF}-\mathrm{TrFE})$ ) are observed for 1-bromo-4-iodobenzene on graphite, as seen in Figure 4c.

The increase in the $\mathrm{Br} 3 \mathrm{~d}$ core level binding energy with increasing bromoform coverage on $\mathrm{P}(\mathrm{VDF}-\mathrm{TrFE})$ suggests a repulsive interaction between adsorbate species, or a decrease in the final state screening in photoemission with increasing coverage. While an increasingly unscreened final state, with increased bromoform coverage is consistent with the HOMO-LUMO gap for bromoform adsorbed on $\mathrm{P}(\mathrm{VDF}-\mathrm{TrFE})$, initial state interactions cannot be completely excluded. A stronger bromoform interaction with the substrate polymer than occurs between adjacent bromoform molecules is certainly possible, and indeed likely. This too could lead to an increasing core level binding energy with increasing bromoform coverage. In spite of possible stronger interactions with the substrate than adjacent adsorbate species, bromoform adsorption on $\mathrm{P}(\mathrm{VDF}-\mathrm{TrFE})$ must be weak: chloromethane, with a similar static dipole, is not seen to molecularly adsorb on P(VDFTrFE) at all at $120 \mathrm{~K}$.

The adsorbed species whose signature is evident in photoemission, inverse photoemission and XPS is molecular bromoform. Following bromoform adsorption, the core level XPS bromoform signal is no longer apparent at room temperature, as the adsorbate bromoform desorbs below room temperature (Figure 2, spectrum A, after annealing $3 \mathrm{deg} / \mathrm{s}$ ).

Bromoform desorption from $\mathrm{P}(\mathrm{VDF}-\mathrm{TrFE})$ is not hindered by increasing bromoform coverage. Indeed, the main bromine $3 \mathrm{~d}$ core photoemission intensity increases with coverage, but after each annealing treatment to room temperature, the bromine signal is lost, indicative of bromoform desorption (Figure 3a). Following adsorption on $\mathrm{P}(\mathrm{VDF}-\mathrm{TrFE})$ at $120 \mathrm{~K}$ and photofragmentation of the adsorbed bromoform on $\mathrm{P}(\mathrm{VDF}-\mathrm{TrFE})$ (as in $[9,10,43])$, the bromine $3 \mathrm{~d}$ core level signal is persistent to room temperature and

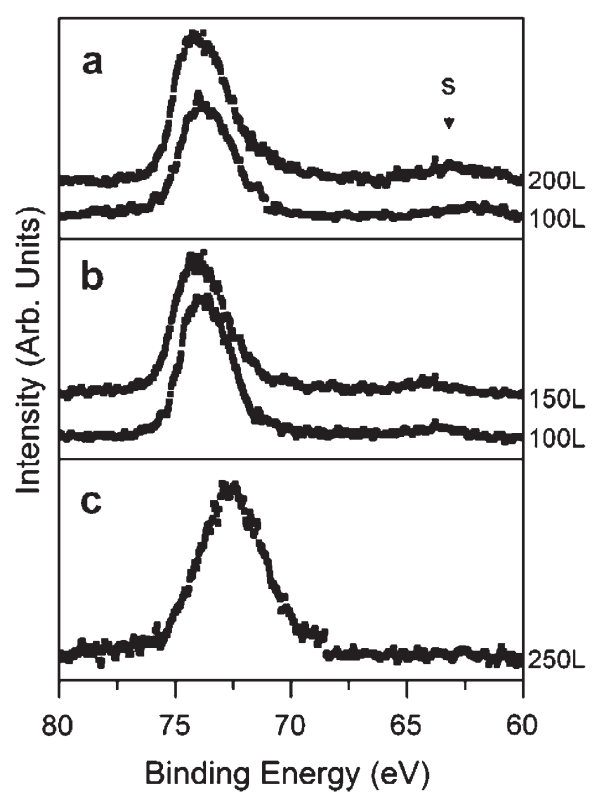

Figure 4. The X-ray photoemission spectra of bromoform on graphite at $140 \mathrm{~K}$ using (a) $1253.6 \mathrm{eV}$ (Mg Ka) and (b) $1486.6 \mathrm{eV}$ ( $\mathrm{Al} \mathrm{Ka)}$. Denoted are the exposures ( 1 Langmuir $(\mathrm{L})=1 \times 10^{-6}$ Torr s). For comparison the X-ray photoemission spectrum of 1-bromo-4-iodobenzene on graphite at $130 \mathrm{~K}$ is shown (c) following a $250 \mathrm{~L}$ exposure, using $1486.6 \mathrm{eV}$ (Al $\mathrm{Ka})$. Photoelectrons were collected along the surface normal. 


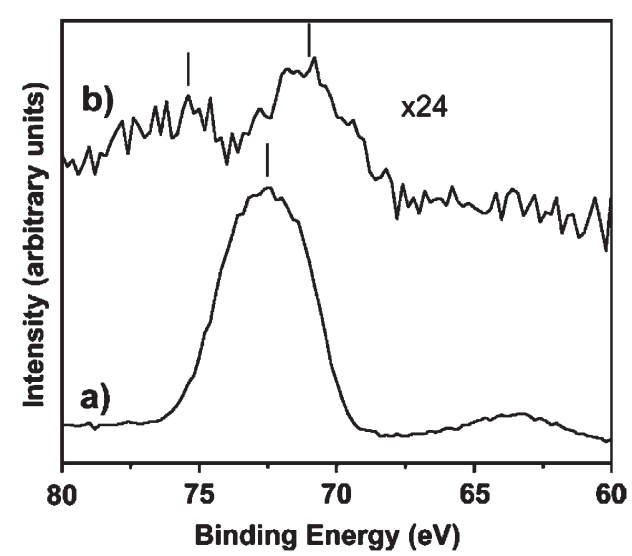

Figure 5. The comparison of the bromine $3 \mathrm{~d}$ core level XPS following $30 \mathrm{~L}$ exposure of bromoform to $\mathrm{P}(\mathrm{VDF}-\mathrm{TrFE})$ at $120 \mathrm{~K}$ (a), to the XPS spectrum following photodecomposition from extensive $\mathrm{Al} \mathrm{Ka}$ radiation. The bromoform fragments in this spectrum are not volatile below $100^{\circ} \mathrm{C}$ (see text).

above $\left(120^{\circ} \mathrm{C}\right)$ (Figure 5). We must infer that dissociative adsorption is not readily reversible and bromine signals, characteristic of molecular fragments, are persistent in XPS to well above room temperature on $\mathrm{P}(\mathrm{VDF}-\mathrm{TrFE})$ (although not so on graphite), so we attribute the spectra in Figure 2 to molecular on P(VDF-TrFE), not dissociative adsorption. The photodissociation of bromoform on $\mathrm{P}(\mathrm{VDF}-\mathrm{TrFE})$ leads to bromine $3 \mathrm{~d}$ XPS features at $71.4 \pm 0.2$ and $75.1 \pm 0.3$ binding energies: binding energies both larger and smaller than the molecular bromoform $3 \mathrm{~d}$ feature at $72.6 \pm 0.1 \mathrm{eV}$ binding energy (Figure 5). These 3d XPS features at $71.4 \pm 0.2$ and $75.1 \pm 0.3$ binding energies are not due to bromoform re-adsorption as bromoform is not seen to adsorb on $\mathrm{P}(\mathrm{VDF}-\mathrm{TrFE})$ at room temperature.

\section{Final state screening and possible dipole-dipole interactions}

The photoemission feature observed with bromoform adsorption on $\mathrm{P}(\mathrm{VDF}-\mathrm{TrFE})$, at approximately $63 \mathrm{eV}$ binding energy, is more difficult to assign. A $9-10 \mathrm{eV}$ chemical shift is difficult to associate with even fragment formation on a polymer surface, or even an absorbed fragment, as this should lead to an increase in binding energy, not a decrease. The feature has far too small or too large a binding energy to be explained by the weak bromine Auger electron lines at $1203 \mathrm{eV}$ (roughly $51 \mathrm{eV}$ binding energy with $\mathrm{Mg} \mathrm{Ka}$ ) and $1167 \mathrm{eV}$ (roughly $87 \mathrm{eV}$ binding energy with $\mathrm{Mg} \mathrm{Ka}$ ) kinetic energies and is not present in the bromine 3d XPS spectra of photodissociated bromoform (Figure 5) or 1-bromo,4-iodobenzene (Figure 4). Assignment of the $63 \mathrm{eV}$ binding energy feature to an Auger electron line can be excluded, as the $63 \mathrm{eV}$ binding energy feature is also evident at about $63.5 \mathrm{eV}$ for very high coverages of bromoform adsorbed on graphite, at two different photon energies $1486.6 \mathrm{eV}(\mathrm{Al} \mathrm{Ka})$ and $1253.6 \mathrm{eV}(\mathrm{Mg} \mathrm{Ka})$. Explanations of the bromoform associated core level photoemission feature at much lower binding energies than the expected $\mathrm{Br} 3 \mathrm{~d}$ cores is likely due to different final state effects, as a bromine Auger electron line like the $\mathrm{M}_{23} \mathrm{M}_{45} \mathrm{~N}_{23}$ Auger lines are unlikely. Other explanations of this very low binding energy $\mathrm{Br} 3 \mathrm{~d}$ XPS feature, like a photoemission final state shake-up or two hole bound state feature, are fairly easy to exclude, as these phenomena also lead to apparent increases in the apparent core level binding energy, not a decrease in binding energy, as observed here.

The ratio of the $63 \mathrm{eV}$ satellite to the main bromine $3 \mathrm{~d}$ core photoemission feature is constant with coverage, for bromoform ad- sorbed on $\mathrm{P}(\mathrm{VDF}-\mathrm{TrFE})$, as seen in Figure $3 \mathrm{~b}$, but increases with increasing coverage for bromoform on graphite. This suggests one possibility for the $63 \mathrm{eV}$ bromine feature is a screened bromine $3 \mathrm{~d}$ photoemission final state for molecular bromoform, not present for photodissociated bromoform on P(VDF-TrFE) (Figure 5) or bromoiodobenzene (Figure 4). Although $\mathrm{P}(\mathrm{VDF}-\mathrm{TrFE})$ is an excellent dielectric (as is bromoform), the polymer substrate does have dipoles that can rotate [24-26]. A strong interaction between adsorbate species and the substrate could lead to charge transfer in the photoemission final state giving rise to a final state akin to the screened final state of molecular nitrogen or carbon monoxide on many metal substrates $[44,45]$. For both $\mathrm{CO}$ and $\mathrm{N}_{2}$, a very large difference in the XPS core level binding energies is observed between the screened and unscreened final states, as is observed here for bromoform. Unlike adsorbed $\mathrm{CO}$ and $\mathrm{N}_{2}$ on many metal substrates, for bromoform adsorption on $\mathrm{P}(\mathrm{VDF}-\mathrm{TrFE})$ and graphite, it is the unscreened final state (higher binding energy) features that are favored, while for $\mathrm{CO}$ and $\mathrm{N}_{2}$, the screened final state is favored.

Dipole rotation leading to increased screening in the final state would be generally weak in the insulating systems described here, but can occur from transient dipole rotation in the ferroelectric P(VDF-TrFE) substrate as well as by adjacent bromoform molecules, if there is sufficient intermolecular interaction. This dipole rotation by adjacent bromoform molecules, leading to increased photoemission final state screening might explain why this far smaller binding energy XPS feature is also seen for very high bromoform adsorption coverages on graphite (Figure $5)$, although weaker in intensity than observed for bromoform on P(VDF-TrFE).

An interaction with the substrate and adjacent bromoform molecular dipoles could lead to very different final states if the dipoles reverse during the photoemission process. Although photoemission is a relatively fast process with respect to single dipole reversal (about a nanosecond for $\mathrm{P}(\mathrm{VDF}-\mathrm{TrFE})$ ), a realignment of an adjacent dipole could bring more charge in close proximity to the bromoform ion final state leading to a more "screened" final state, and effectively decrease the binding energy. The energy difference between screened and unscreened finals states can be quite large [44], and indeed larger than many chemical shifts. While other intermolecular interactions between adsorbates could also lead to different final states, the large HOMO-LUMO gap suggests that such effects like charge transfer to unoccupied states is unlikely, although the large frontier orbitals of bromine would tend to enhance such interactions. The effect of electronic excitations is seen with water thermal desorption from $\mathrm{P}(\mathrm{VDF}-\mathrm{TrFE})$, $[37,38]$ but not with similar polymers where the dipole is sterically hindered from rotation $[38,46]$.

The problem with this model of final state screening due to dipole rotation is that dipole rotation for $\mathrm{P}(\mathrm{VDF}-\mathrm{TrFE})$ as well as adjacent bromoform is slow compared to the photoemission process. In the case of adjacent bromoform screening the photoemission final states, there is no need for complete dipole reversal and realignment, as partial molecule reorientation of an adjacent molecule could have a profound effect. Bromoiodobenzene being far larger would have any rotation or molecular realignment more readily hindered by steric effects and thus might address why this weak core level feature at $9-10 \mathrm{eV}$ smaller binding energies is not observed at all with bromoiodobenzene on graphite and other larger bromine functionalized organics on non-ferroelectric substrates.

Another possible dipole excitation could be invoked to explain the very low $63 \mathrm{eV}$ binding energy $\mathrm{Br} 3 \mathrm{~d}$ photoemission feature. If there is a large population of long lived exciton states in adsorbed bromoform, then collapse of the exciton during the photoemission process could impart that energy to the outgoing photoelectron. Given the size of the bromoform HOMO-LUMO gap (Figure 1), 
this explanation is consistent with the nearly $10 \mathrm{eV}$ additional kinetic energy needed for a $63 \mathrm{eV}$ binding energy $\mathrm{Br} 3 \mathrm{~d}$ satellite.

A dynamic dipole interaction with some substrates is likely for bromoform, because the ratio of potentially screened and unscreened final state intensities is independent of bromoform coverage on $\mathrm{P}(\mathrm{VDF}-\mathrm{TrFE})$, as seen in Figure $3 \mathrm{~b}$, but is coverage dependent for bromoform adsorption on graphite. Bromoform absorption might explain the increase in sticking coefficient with increasing coverage, as with water absorption on $\mathrm{P}(\mathrm{VDF}-\mathrm{TrFE})$ not only is the initial absorption sterically hindered, but what water is absorbed, remains difficult to identify in electron spectroscopies [47]. No evidence of an absorbed bromoform phase was, however, found. Unlike water, where absorption initially dominates over adsorption on $\mathrm{P}(\mathrm{VDF}-\mathrm{TrFE})[37,38]$, an absorbed phase of bromoform is not evident in photoemission and does not explain the approximately $9-$ $10 \mathrm{eV}$ energy difference in the two possible $3 \mathrm{~d}$ XPS core features, given this is also seen with bromoform adsorption on graphite. A 9-10 eV shift is far too much for a bromine chemical shift for largely associative absorption of bromoform on or in a dielectric polymer.

\section{Summary}

In summary, we find evidence for molecular adsorption of bromoform on P(VDF-TrFE) and graphite. As with bromoform adsorption on ice $[9,10]$ and chloroform adsorption on calixarene [23] layers, dipole interactions between the adsorbate and substrate may play a key role in the interaction energetics. Strong adsorbate intermolecular interactions with the substrate may also play a role in dipole alignment of the bromoform. An absence of bromoform wetting of PVDF would give rise to different chemical sites for adsorbed bromoform, but all such different bromoform adsorbed species should have larger than expected binding energies, not smaller than expected. In general, unlike water [38], bromoform absorption into polymers like $\mathrm{P}(\mathrm{VDF}-\mathrm{TrFE})$ is not expected [48].

\section{Acknowledgments}

This research was supported by the National Science Foundation through Grant Nos. CHE-0415421 and CHE-0650453. The authors would like to acknowledge the assistance of David Wisbey, Stephen Ducharme and Paul Burrow, and helpful conversations with R.G. Jones.

\section{References}

[1] M. Grunze and P.A. Dowben, Appl. Surf. Sci. 10 (1982), p. 209.

[2] R. Tate, D.C. Driscoll and G.Z. Stauf, Naturforschung 41a (1986), p. 1091.

[3] R.G. Jones and C.A. Clifford, Phys. Chem. Chem. Phys. 1 (1999), p. 5223.

[4] St.J. Dixon-Warren, D.V. Heyd, E.T. Jensen and J.C. Polanyi, J. Chem. Phys. 98 (1993), p. 5954.

[5] St.J. Dixon-Warren, E.T. Jensen and J.C. Polanyi, J. Chem. Phys. 98 (1993), p. 5938

[6] R.G. Jones, I. Shuttleworth, C.J. Fisher, J.J. Lee, S.L. Bastow, R. Ithnin, J. Ludecke, M.P. Skegg, D.P. Woodruff and B.C.C. Cowie, Phys. LowDim. Struct. 11-12 (2001), p. 1.

[7] A. Bah, T. Ceva, B. Croset, N. Dupont-Pavlovsky and E. Ressouche, Surf. Sci. 395 (1998), p. 307.

[8] J.M. Chen, S.C. Yang and Y.C. Lin, Surf. Sci. 391 (1997), p. 278.

[9] M.L. Grecea, E.H.G. Backus, A.W. Kleyn and M. Bonn, Surf. Sci. 600 (2006), p. 3337.

[10] M.L. Grecea, E.H.G. Backus, A.W. Kleyn and M. Bonn, J. Phys. Chem. B 109 (2005), p. 17574.

[11] J.E. Schaff and J.T. Roberts, Surf. Sci. 426 (1999), p. 384.

[12] J.E. Schaff and J.T. Roberts, J. Phys. Chem. 100 (1996), p. 14151.

[13] G.A. Kimmel, N.G. Petrik, Z. Dohnalek and B.D. Kay, J. Chem. Phys. 126 (2007), p. 114702.
[14] Z. Dohnalek, G.A. Kimmel, R.L. Ciolli, K.P. Stevenson, R.S. Smith and B.D. Kay, J. Chem. Phys. 112 (2000), p. 5932.

[15] L.G. Rosa, Jie Xiao, Ya.B. Losovyj, Yi Gao, I.N. Yakovkin, X.C. Zeng and P.A. Dowben, J. Am. Chem. Soc. 127 (2005), p. 17261.

[16] G.A. Kimmel, N.G. Petrik, Z. Dohnalek and B.D. Kay, Phys. Rev. Lett. 95 (2005), p. 166102.

[17] H. Qu, W. Yao, T. Garcia, J. Zhang, S. Ducharme, P.A. Dowben, A.V. Sorokin and V.M. Fridkin, Appl. Phys. Lett. 82 (2003), p. 4322.

[18] S. Palto, L. Blinov, E. Dubovik, V. Fridkin, N. Petukhova, A. Sorokin, K. Verkovskaya, S. Yudin and A. Zlatkin, Europhys. Lett. 34 (1996), p. 465.

[19] J. Choi, P.A. Dowben, S. Ducharme, V.M. Fridkin, S.P. Palto, N. Petukhova and S.G. Yudin, Phys. Lett. A 249 (1998), p. 505.

[20] J. Choi, C.N. Borca, P.A. Dowben, A. Bune, M. Poulsen, S. Pebley, S. Adenwalla, S. Ducharme, Lee Robertson, V.M. Fridkin, S.P. Palto, N. Petukhova and S.G. Yudin, Phys. Rev. B 61 (2000), p. 5760.

[21] J. Xiao, L.G. Rosa, M. Poulsen, D.-Q. Feng, S. Reddy, J.M. Takacs, L. Cai, J. Zhang, S. Ducharme and P.A. Dowben, J. Phys. Condens. Mat. 18 (2006), p. L155.

[22] C.-G. Duan, W.N. Mei, J.R. Hardy, S. Ducharme, J. Choi and P.A. Dowben, Europhys. Lett. 61 (2003), p. 81.

[23] K.-D. Schierbaum, A. Gerlach, W. Gøopel, W.M. Müller, F. Vögtle, A. Dominik and H.J. Roth, Fresenius J. Anal. Chem. 349 (1994), p. 372.

[24] T. Furukawa, Phase Transit. 18 (1989), p. 143.

[25] L.M. Blinov, V.M. Fridkin, S.P. Palto, A.V. Bune, P.A. Dowben, S. Ducharme, Uspekhi Fizicheskikh Nauk [Russian edition vol.] 170 (2000) 247; Physics Uspekhi [English edition volume] 43 (2000) 243.

[26] S. Ducharme, S.P. Palto and V.M. Fridkin In: H.S. Nalwa, Editor, Handbook of Thin Film Materials, Ferroelectric and Dielectric Films vol. 3, Academic Press, New York (2002), pp. 546-595 Chapter 11.

[27] J. Choi, P.A. Dowben, S. Pebley, A. Bune, S. Ducharme, V.M. Fridkin, S.P. Palto and N. Petukhova, Phys. Rev. Lett. 80 (1998), p. 1328.

[28] J. Choi, S.-J. Tang, P.T. Sprunger, P.A. Dowben, V.M. Fridkin, A.V. Sorokin, S.P. Palto, N. Petukhova and S.G. Yudin, J. Phys. Condens. Mat. 12 (2000), p. 4735.

[29] L.G. Rosa, Ya.B. Losovyj, J. Choi and P.A. Dowben, J. Phys. Chem. B 109 (2005), p. 7817.

[30] P.A. Jacobson, Luis G. Rosa, C.M. Othon, Kristin Kraemer, A.V. Sorokin, Stephen Ducharme and P.A. Dowben, Appl. Phys. Lett. 84 (2004), p. 88.

[31] L.G. Rosa, P.A. Jacobson, R. Lemoine and P.A. Dowben, J. Appl. Crystallogr. 37 (2004), p. 672

[32] D.N. Mcllroy, J. Zhang, P.A. Dowben and D. Heskett, Mater. Sci. Eng. A 217/218 (1996), p. 64.

[33] D.K. Chambers, S. Karanam, D. Qi, S. Selmic, Ya.B. Losovyj, L.G. Rosa and P.A. Dowben, Appl. Phys. A 80 (2005), pp. 483-488.

[34] I.N. Yakovkin and P.A. Dowben, Surf. Rev. Lett. 14 (2007), p. 481.

[35] A.M. Scheer and P.D. Burrow, J. Phys. Chem. B 110 (2006), p. 17751.

[36] J. Xiao, M. Poulsen, D.S. Reddy, J.M. Takacs, Ya.B. Losovyj and P.A. Dowben, Polym. Eng. Sci. 48 (2008), pp. 1649-1654.

[37] L.G. Rosa, P.A. Jacobson and P.A. Dowben, J. Phys. Chem. B 110 (2006), p. 7944.

[38] P.A. Dowben, L.G. Rosa, C.C. Ilie and Z. Physikalische, Chemie 222 (2008), p. 755.

[39] J.E. Ortega, F.J. Himpsel, Dongqi Li and P.A. Dowben, Solid State Commun. 91 (1994), p. 807.

[40] O.Gunnarssonand K.Schönhammer,Phys. Script.21(1980),pp.575-579. K. Wandelt and B. Gumhalter, Surf. Sci. 140 (1984), pp. 355-376.

[41] C.D. Wagner, J. Vac. Sci. Technol. 15 (1978), p. 518.

[42] R. Spohr, T. Bergmark, N. Magnusson, L.O. Werme, C. Nordling and K. Siegbahn, Phys. Script. 2 (1970), p. 31.

[43] W.S. McGivern, O. Sorkhabi, A.G. Suits, A. Derecskei-Kovacs and S.W. North, J. Phys. Chem. A 104 (2000), p. 10085.

[44] C.R. Brundle, P.S. Bagus, D. Menzel and K. Hermann, Phys. Rev. B 24 (1981), p. 7041.

[45] E. Umbach, Solid State Commun. 51 (1984), p. 365.

[46] P.A. Jacobson, C.C. Ilie, I.N. Yakovkin, M. Poulsen, D.S. Reddy, J.M. Takacs and P.A. Dowben, J. Phys. Chem. B 110 (2006), p. 15389.

[47] Luis G. Rosa, I.N. Yakovkin and P.A. Dowben, J. Phys. Chem. B 109 (2005), p. 14189.

[48] J.N. Jones, G.D. Miller, in: A.G. Collins, A.I. Johnson (Eds.), Groundwater contamination: field methods, ASTM STP 963, American Society for Testing and Materials, Philadelphia, 1988, pp. 185-198. 